\author{
Darren O’Connell \\ and \\ Barry O'Grady \\ School of Economics and Finance \\ Curtin University
}

ISSN: 1835-9450

09.02 


\title{
THE BUY-WRITE STRATEGY, INDEX INVESTMENT AND THE EFFICIENT MARKET HYPOTHESIS: MORE AUSTRALIAN EVIDENCE ${ }^{1}$
}

\author{
Darren O'Connell \\ doconnell@arach.net.au \\ Barry O'Grady \\ Barry.o'grady@cbs.curtin.edu.au \\ Curtin University of Technology \\ GPO Box U1987 \\ Perth
}

The purpose of this study is to examine the performance of an index buy-write strategy in the using three portfolios based on the Whaley (2002) approach; one for a portfolio of bank bills, one for a benchmark index and the third for a benchmark index hedged by index call options. The study uses Australian daily data between 1991 and 2006 and confirms that the buy-write strategy outperforms the index-only portfolio on both a risk and return basis. In addition, the strategy is seen to produce abnormal returns and therefore provides further evidence that appears to violate the efficient market hypothesis.

Keywords: Buy-write, covered call, index portfolios, total risk, systematic riskadjusted excess returns, efficient market hypothesis.

\footnotetext{
${ }^{1}$ The authors would like to thank Richard Dale from Norgate Investor Services, Julian Maingard from the Australian Securities Exchange and Tom Mills from Standard and Poors for generously providing complimentary proprietary information and volumous data that assisted in understanding this subject.
} 


\section{Introduction}

In recent years, many investors have turned their attention to investments with higher yields that generate steady income and lower volatility for their portfolios. One way to achieve this is by using the buy-write strategy ${ }^{2}$ in which an investor buys a stock or basket of stocks, and simultaneously sells call options ${ }^{3}$ that correspond to the stock or basket. This strategy can be used to enhance a portfolio's risk-adjusted returns and reduce volatility at times when an investor is willing to forgo some upside potential in the event of a bull market in equities.

Initially, the buy-write/covered call strategy was shunned after a number of academic studies, which were published during the 1970s by scholars such as Merton and Scholes, doubted its value because risk reduction was usually gained at the expense of return. As financial markets evolved and option-pricing models became more sophisticated, the strategy was seen to deliver greater benefits. This was particularly the case for portfolio managers who were seeking to stabilise their portfolios without the need to liquidate during the bear markets that followed the 1987 equity market crash. Indeed, the strategy became so popular in the US that it spawned a Chicago Board Options Exchange (CBOE) index, which can be used by investors, to benchmark the performance of buy-write option strategies (CBOE, 2002).

Research on the US market provides some confirmation that the implied standard deviation of call options on index futures is greater than "realised volatility" suggesting that index call options are over-priced. This appears to be the most compelling reason why the buy-write and covered call strategies outperform indexonly portfolios. Studies conducted in Australia find similar evidence of option mispricing although whether this is due to local portfolio managers competing for

\footnotetext{
${ }^{2}$ A buy-write strategy is commonly, although inaccurately, known as a covered call strategy.

${ }^{3}$ In virtually all the covered call/buy-write strategies investigated, the authors note that the options used were American-style, in that the options can be exercised at any point up to the expiry.
} 
insurance or the lack of liquidity is unclear. Regardless, it is likely that the mispricing present in the Australian market allows the local buy-write strategy to outperform the index-only portfolio. This study replicates the Whaley (2002) index model by application to the Australian equities market. It examines the performance of a buywrite strategy, which involves the purchase of an index as a proxy for a portfolio of stocks underlying the benchmark index and simultaneously writing just out-of-the money American-style index options versus an index-only portfolio.

The results discussed here support those established by Whaley and others that the buy-write index strategy generates not only a higher return than the index-only portfolio but also exhibits a lower variance. On a total risk and systematic riskadjusted basis, the buy-write strategy outperforms the index portfolio. This leads into a discussion on whether the strategy generates an abnormal return and if so would not this constitute a violation of the Efficient Market Hypothesis (EMH)? The rationale behind implementing a buy-write index strategy, (i.e. enhancement of returns or reduction of portfolio risk), violates a number of key assumptions underlying EMH which, as demonstrated by the results, can lead to the identification and exploitation of previously unidentified market and institutional inefficiencies.

The remainder of this paper is structured as follows. The next section reviews the available literature while section 3 describes the methodology and data relevant to the study. This is followed by section 4, which discusses the results and performance; section 5 looks at the strategy in relation to EMH and section 6 concludes. 


\section{Literature Review}

\section{$2.1 \quad$ Development of the buy-write}

Historically, the available literature on either buy-write or covered call strategies has been thin due to the perception that they delivered little benefit to the investor. This view was reinforced by the seminal work of Merton, Scholes and Gladstein (1978) who studied an equally weighted, fully hedged covered call strategy based on a portfolio of 136 US stocks. This portfolio is rebalanced every six months and option prices are based on the Black-Scholes pricing methodology. They find that the covered call strategy reduces both risk and return, and, more importantly, induces negative skewness that becomes slowly positive as deeper out-of-the-money calls are used. These results imply that the performance of the covered call strategy will improve, relative to a stocks-only portfolio, if higher options prices can be obtained than those provided by the Black-Scholes model. Four years later, Merton, Scholes and Gladstein (1982) investigated the protective put strategy on the same basis. This time though, option prices were provided by Merton's (1973) early exercise BlackScholes model, which resulted in reduced portfolio risk and return. Findings indicate that in-the-money puts lower returns and variance more than out-of-the-money puts but as before, mispriced option contracts will produce increased gains for moderate increases in variance.

Bookstaber and Clarke (1984) use mathematical algorithms to compare the distributions between stocks and combinations of stock/option portfolios. They find that writing call options on a portfolio lead to an asymmetric payoff, in effect, a rightward shift in the entire distribution followed by a truncation of payoffs at a pricedetermined pivot point. Bookstaber and Clarke (1985) show that, in reality, the put option portfolio truncates the negative tail of the distribution introducing positive 
skewness while the call portfolio does the opposite. Therefore, the latter decreases the desirable part of the variance while the former decreases the negative portion. Given the asymmetric return distribution of option portfolios and the difference in risks of the two strategies, simple, one-dimensional measures of risk such as variance and performance measures such as the Sharpe or Treynor ratios will cause erroneous conclusions.

To overcome this handicap, Moran and Naciri (1990) examine these option strategies using a stochastic dominance framework. They show that it is indeed possible to create a more mean/variance efficient portfolio using the covered call technique. Lhabitant (1998) goes further and examines the problem of performance measurement for non-symmetrical return distributions on data from 1975 to 1996 such as the covered call and the protective put option strategies. He claims that meanvariance performance measures are inadequate because they do not account for the third and fourth moments of the return distribution (i.e. skewness and kurtosis respectively). Under this framework, covered call writing will mean/variance dominate the stock, which itself will mean/variance dominate the protective put. As a consequence, using measures such as the Sharpe ratio for option strategies actually overstates the performance of the covered call strategy and understate the performance of the protective put strategy. As an alternative, Lhabitant proposes the use of the first and second-degree stochastic dominance with a risk-free asset as a performance measure since this requires few restrictions on investor preferences and no restriction on asset return distribution.

As yet however, academics and practitioners alike are divided on the question of whether a generally accepted performance measure has been devised to accurately explain non-linear return distributions and this may be the reason why the buywrite/covered call strategy was ignored for so long. 
Interest in the strategy grew considerably following the publication of Whaley's (2002) landmark study. It appears that this work was the first to really subject the index buy-write strategy to a full rigorous analysis over a timeframe that incorporated both phases of the market and spawned a number of related works thereafter. Whaley examines a strategy involving the purchase of a portfolio underlying the S\&P 500 Index and simultaneously writing slightly out-of-the money S\&P 500 Index call options traded on the CBOE.

Whaley demonstrates that such a passive buy-write strategy, on average, generated positive risk-adjusted returns over the period June 1988 to December 2001, both before and after controlling for the cost of trading the option. He finds that the index portfolio produced a mean monthly return of 1.172 per cent with a standard deviation of 4.103 per cent. In contrast, the CBOE buy-write index (the S\&P 500 Index fully covered with call options) returned 2.340 per cent with a standard deviation 2.663 per cent. In other words, the buy-write index produced a superior monthly return compared to the S\&P500 Index, but at less than 65 per cent of the risk level. Furthermore, by matching the risk level of the buy-write index to the S\&P 500 Index, the former returned 0.322 per cent more than the latter. This work formed the basis of the resulting S\&P 500 BuyWrite Index (BXM) launched by the CBOE in April 2002.

The BXM achieved this abnormally higher return over the period June 1988 through December 2000. Stux and Fanelli, and Schneeweis and Spurgin, cited in Whaley, suggest that the volatilities implied by S\&P 500 option prices are high relative to realised volatility. Bollen and Whaley (2004) argue that there is excess buying pressure on S\&P 500 index puts by active investment managers frequently using exchange-traded options as a risk reduction tool. Since there are no natural counterparties to these trades, market makers must step in to absorb the imbalance. As 
their inventories grow, implied volatility will rise relative to actual return volatility. The difference is the market maker's compensation for hedging costs and/or exposure to volatility risk. The implied volatilities of the corresponding calls also rise from the reverse conversion arbitrage supporting the put-call parity theorem.

Consistent with this proposition, Whaley shows that the implied volatility of index calls is greater than historic or realised volatility, although the difference was not constant over time suggesting variation in the demand for portfolio insurance. The difference was persistently positive, averaging 234 basis points over the evaluation period. To prove that the high level of implied volatility was at least partially responsible for the abnormal returns generated by the $\mathrm{BXM}$, the index was reconstructed using theoretical option values derived from the Black-Scholes-Merton (1973) model rather than historical market prices. Again the BXM outperformed the S\&P 500 index portfolio but only marginally, particularly so when the theoretically superior semi-variance measure is adopted. This finding confirms Merton, Scholes and Gladstein's (1978) conjecture that an improved buy-write performance would result if higher option prices could be obtained than those suggested by static models, such as Black-Scholes. Whaley concludes that at least some of the BXM's risk adjusted performance was due to this mispricing of options caused by portfolio insurance demands, and hence any strategies seeking to exploit this anomaly should prove profitable.

Using Whaley's principles, the first Australian index buy-write study was undertaken by Jarnecic (2004). This author analyses the risk and return associated with the purchase of an equities portfolio based on the S\&P/ASX 200 index and writing out-of-the-money index call options over the period 1987 to 2002 . The buywrite strategy produced an excess return, relative to the index-only strategy of 0.56 per cent for a standard deviation of 5.78 per cent versus 6.15 per cent, which were 
considered stronger than Whaley's results. This work was based on quarterly data that yielded a mere 60 data points and suffers from too brief an analysis on which to fully understand the index buy-write strategy's effectiveness in Australia's investment landscape.

The most recent study on the buy-write strategy was undertaken by Callan and Associates (2006), who extended Whalley's original work by analysing a longer timeframe. Like Whalley, they find that the BXM does not out perform the S\&P 500 per se but its variability of returns is almost two-thirds lower. However, on a riskadjusted return, as measured by the Stutzer index, the BXM is superior to an indexonly investment. Their study also shows, as this study does, that the buy-write strategy should be considered as a suitable standalone investment and portfolio diversification tool.

\subsection{How option strategies can violate the EMH}

In an efficiently functioning securities market, the risk-adjusted return of a buy-write strategy (or any other option-based strategy for that matter) should be no different from the underlying market portfolio. Recent years have seen a reinvestigation of the EMH of financial market performance. A hypothesis that once had widespread acceptance, the EMH has not fared so well under newer tests. The following brief discussion looks at the principle assumptions that tend to be violated when investors adopt an option strategy.

Guillaume et al (1995) present a number of stylized facts from a study concerning the spot intra-daily foreign exchange markets. The study first describes intra-daily data and proposes a set of definitions for the variables of interest. Empirical regularities of the foreign exchange intra-daily data are then grouped under three major topics: the distribution of price changes, the process of price formation 
and the heterogeneous structure of the market. The stylized facts surveyed in this paper shed new light on the market structure that appears composed of heterogeneous agents, rather than EMH assumed homogenous. It also poses several challenges such as the definition of price and of the time-scale, the concepts of risk and efficiency, the modelling of the markets and the learning process.

In analysing one of the critical assumptions of EMH, namely that investors are homogenous in their beliefs, Brock and Hommes (1998) investigate the performance of a number of structural asset pricing models. Citing an earlier empirical work, the authors' show that simple technical trading strategies applied to the Dow Jones index might outperform several popular EMH stochastic finance models such as the random walk. This result led them to believe that the market contains two typical investor types. The first is described as a rational 'smart money' trader who believes that asset prices are determined solely by EMH fundamental value, as given by the present discounted value of future dividends. The second is known as a 'chartists' or technical analyst, who believes that the price discounts all known information and trends evident on price charts repeat over time. If there are two types of investors who differ in their beliefs, then the assumption of homogeneity is violated. Heterogeneous beliefs about asset price dynamics coupled with a 'high intensity' of investment choices causes volatile oscillations around an unstable EMH fundamental that can lead to abnormal returns. 


\section{Methodology and Data}

\subsection{Overview of the $S \& P / A S X 200$ Buy Write Index}

The S\&P/ASX 200 Buy Write Index (XBW) is a passive total return index. The underlying index is the S\&P/ASX200 Index over which an S\&P/ASX200 Index call option is sold each quarter. In Australia, index option series expire each quarter, so at the time of selection, each option used in the index will have 3 months to expiry. Once an option series has been selected, it is held to maturity. A new series is selected at the expiry of the current one based on the nearest out of the money strike and the closest available expiry.

\subsection{The $S \& P / A S X$ Buy Write Index}

In 2004, the ASX adopted the methodology used by Whaley and launched the S\&P/ASX XBW Index and developed a set of historical data adjusted for all the institutional changes described presently. Responsibility for the ongoing maintenance and calculation of the XBW index was given to Standard \& Poor's. They subsequently refined the Whaley (2002) approach by adding an extra level of rigour that more accurately mirrors the current institutional environment.

\subsubsection{The ASX/Jarnecic Methodology}

In constructing the return on the buy-write strategy, Jarnecic (2004) followed Whaley very closely, whilst accounting for the peculiarities of the Australian market. The return on the buy-write strategy was calculated assuming the index portfolio is purchased and a just-out-of-the-money index call option was written each quarter and held to expiry. The following expression was used to calculate the quarterly returns on the buy-write strategy: 


$$
R_{t}=\frac{A I_{t}-A I_{t-1}-\left(C_{t}-C_{t-1}\right)}{A I_{t-1}-C_{t-1}}
$$

where $A I_{t}$ is the level of the accumulation index of day $t$ and $C_{t}$ is the price of a just out-of-the-money index call option on day $t$. The return on the buy-write strategy is compared to the return on the Accumulation Index-only portfolio, as well as the return on a strategy involving the purchase of a 90-day bank bill, which is held to expiration.

To generate the history of the XBW returns, the methodology adopted had to recognise the changes to Australian indices that occurred during 2000 and 2001. Specifically, for each quarterly expiration date, Jarnecic (2004) constructed a hybrid buy-write history using the following data specifics:

For index options up until March 2000, the exercise and closing prices for just out-of-the-money, nearest to maturity SFE Share Price Index option ${ }^{4}$ contracts were used, after which values for the S\&P/ASX200 Index option contracts were used.

The settlement price of the expiring option contract (SPI or XJO option) is based on the closing value of the relevant stock index that day.

The closing value of the All Ordinaries Accumulation Index is used until March 2000, after which closing values of the S\&P/ASX200 Accumulation Index were extracted.

Bank bill rates were also used in this analysis, and these were sourced from the Reserve Bank of Australia's (RBA) website. ${ }^{5}$

\footnotetext{
${ }^{4}$ The SFE Share Price Index option contract was based on the All Ordinaries Index prior to the introduction of S\&P indices.

${ }^{5}$ The Australian government ceased issuing short-term treasury notes in June 2002 and the overnight cash rate is not investable making Bank Accepted Bills the only proxy for the risk free rate.
} 


\subsubsection{Standard \& Poor's Methodology}

Standard \& Poor's Custom Index Solutions assumed calculation of the S\&P/ASX Buy Write Index from May 2004 onwards. The calculation methodology was adjusted slightly to better reflect the total return nature of a passive buy-write strategy whereby dividends in the underlying index are re-invested in the index on the ex-date. However, the two methodologies are fundamentally the same as the following discussion on the algorithm used by Standard \& Poor's in calculating the XBW will demonstrate ${ }^{6}$ - see (2) where $t$ is the current trading day, $t-1$ is the previous trading day, $X B W$ is the $\mathrm{S} \& \mathrm{P} / \mathrm{ASX}$ Buy Write Index level, $X J O$ is the official closing level for the S\&P/ASX 200 Index, $C$ is the call option value, $D$ is the theoretical dividend payable on the XJO index, and $R$ is the rollover adjustment. These terms are explained in more detail below.

$$
X B W_{t}=\frac{X J O_{t}-C_{t}+D_{t}+R_{t}}{X J O_{t-1}-C_{t-1}} \times X B W_{t-1}
$$

Call Option Value. The call option is valued at the margin price for the current trading day. The margin price as defined and calculated by the ASX, and is the midpoint between the bid and offer price (rounded up to the nearest cent) and is subject to adjustment by ASX. The margin price is sourced from the ASX Signal D00AD snapshot (taken at 5 p.m. AEST).

Dividend. The implied dividend paid to the S\&P/ASX 200 Price Index is expressed in index points and is calculated as the excess returns of the S\&P/ASX 200 Accumulation Index over and above the S\&P/ASX 200 Price index. This approach allows Standard \& Poor's to add the dividend (in points) to the index level - see (3)

\footnotetext{
${ }^{6}$ It is interesting to note that the two methods used differ only in their measurement objectives; the ASX / Jarnecic version measures return but to convert this to an index level requires the former to be multiplied by the previous period's index level, as per S\&P.
} 
where $A$ is the S\&P/ASX 200 Accumulation (or Total Return) Index level, $P$ is the S\&P/ASX 200 Price Index level.

$$
\operatorname{Div}_{t}=\left(\frac{A_{t}}{A_{t-1}}-\frac{P_{t}}{P_{t-1}}\right) \times P_{t-1}
$$

Rollover Adjustment. The rollover adjustment represents the net profit/(loss) from writing the new call option and settlement of the expiring call option on the expiry date. Option expiry generally occurs quarterly on the third Thursday of each calendar quarter.

If the current trading day is not the option expiry date, the rollover adjustment equals zero. If the current trading day is the same as the option expiry date, two events occur - settlement obligations from the expiring call option and writing a new out-ofthe-money call option.

Settlement obligations (SO) may arise when the S\&P/ASX 200 Index Closing Settlement Price (CSP) is greater than the exercise price of the expiring option $(y)$. The loss from the expiring call option is calculated as the lower of zero and the difference between the exercise price (X) minus the CSP.

$$
S O_{y}=\min \left(0, X_{y}-C S P_{t}\right)
$$

The rollover adjustment (RA) is therefore equal to the proceeds from writing the new call option plus any settlement obligations from the expiring option.

$$
R A_{t}=C_{z}+\min \left(0, X_{y}-C S P_{t}\right)
$$

Where $t$ is the current trading day AND the expiry date of the current option $(y), y$ is the current period call option, $z$ is the next period call option, $C_{z}$ is the new call option sold at the ASX margin price (taken at 5 p.m. AEST), $X_{y}$ is the exercise price of the current expiring call option, and CSP is the Opening Price Index Calculation (OPIC) as used for ASX futures and options settlement. 


\subsection{Portfolio Performance Measures}

The most commonly applied measures of portfolio performance are the Sharpe [1966] ratio, Modogliani and Modogliani's [1997] $\mathrm{M}^{2}$ Ratiom, Treynor [1965] ratio and Jensen's [1968] Alpha. All four performance measures are shown below.

$$
\begin{gathered}
S=\frac{\left(r_{p}-r_{f}\right)}{\sigma_{p}} \\
M^{2}=\left(r_{p}-r_{f}\right)\left(\frac{\sigma_{m}}{\sigma_{p}}\right)-\left(r_{m}-r_{f}\right) \\
T=\frac{\left(r_{p}-r_{f}\right)}{\beta_{p}} \\
\alpha_{p}=r_{p}-\left(r_{f}+\beta_{p}\left(r_{m}-r_{f}\right)\right)
\end{gathered}
$$

In assessing ex-post performance, the parameters of the formulae are estimated from historical returns over the time horizon. First, $r_{f}, r_{m}$ and $r_{p}$ are the mean daily returns of a "risk-free" bank bill investment, the composite accumulation, or market index and the portfolio (XBW) respectively. Second, $\sigma_{m}$ and $\sigma_{p}$ are the standard deviations of the returns (total risk) of the market and the portfolio. Finally, $\beta_{p}$ is the portfolio's systematic risk (beta) estimated by ordinary least squares (OLS) regression of the excess returns of the portfolio on the excess returns of the market $(10)$.

$$
\left(r_{p, t}-r_{f, t}\right)=\alpha_{p}+\beta_{p}\left(r_{m, t}-r_{f, t}\right)+\varepsilon_{p, t}
$$

The regression co-efficient $\alpha_{p}$ captures the systematic performance in the buywrite strategy after adjusting for the beta risk $\left(\beta_{\mathrm{p}}\right)$ of the strategy.

In terms of portfolio performance measurement, traditional risk-adjusted performance measures substitute standard deviation for some variation of downside risk, designed to measure the lower partial moment, i.e. the chance that the return will 
deviate below the benchmark. Semi-standard deviation is a characterisation of the downside risk of a distribution, which represents the standard deviation of all returns

falling below the mean, i.e. to the left of the distribution. The semi-standard deviation is always lower than the total standard deviation of the distribution - see (11).

Returns on risky assets, when they exceed the risk-free rate of interest, do not affect risk. To account for possible asymmetry of the portfolio return distribution, the Sharpe and M-squared ratios are recalculated using the estimated semi-standard deviation of returns of the market and the portfolio for $\sigma_{m}$ and $\sigma_{p}$.

The systematic risk-based portfolio performance measures such as Treynor ratio and Jensen's Alpha, also have theoretical counterparts in a semi-standard deviation framework with the only difference being the estimate of systematic risk. To estimate beta, a regression through the origin is performed using the excess returns of the market and the portfolio. Where excess returns are positive, they are replaced with a zero value - see (12).

$$
\begin{gathered}
\text { Total Risk }_{i}=\sqrt{\frac{\sum_{t=1}^{T} \min \left(R_{i, t}-R_{f, t}, 0\right)^{2}}{T}} \\
\text { Where } \mathrm{i}=\mathrm{m}, \mathrm{p} . \\
\min \left(r_{p, t}-r_{f, t}, 0\right)=\beta_{p} \min \left(r_{m, t}-r_{f, t}, 0\right)+\varepsilon_{p, t}
\end{gathered}
$$




\subsection{Data}

This study uses daily data to conduct the analysis on the benefits of the Australian index buy-write strategy over the period 31 December 1989 to 31 December 2006 equating to a total of 3,772 data points.

All Ordinaries Accumulation Index data was used from 31 December 1991 to 31 March 2000 and the S\&P/ASX 200 Accumulation Index data was used thereafter. The index values on the changeover data were identical for each respective index thus providing a seamless price series and henceforth the index-only, or market, portfolio, will be referred to as the Composite Accumulation Index (CAI).

The All Ordinaries and S\&P/ASX 200 Accumulation indices data required for this study were downloaded from Datastream. The XBW historical data was obtained from Standard and Poor's. Historical bank bill rates were sources from the RBA website.

\section{Results and Performance}

\subsection{Properties of Realised Daily Returns of the XBW}

Table 1 provides comparative summary statistics for the realised monthly and annual returns of the XBW, the CAI and a 90-day bank bill investment based on daily data.

The compounded monthly return on the XBW was 1.62 per cent, 14 basis points higher than the CAI. Risk, as measured by standard deviation was substantially lower, 2.67 per cent versus 3.53 per cent, which equates to 32 per cent reduction of risk per unit of return. The same observations can be made of the annual return statistics.

The third section of this table provides some daily measures of performance that reveal the XBW's investment characteristics further. For example, the buy-write 
index produced a higher percentage of positive returns compared to the CAI and excess returns were achieved over 47 per cent of the time. Interestingly, the XBW has a lower correlation to the underlying stock index suggesting a further source of portfolio diversification.

Like the US market, the results reported in Table 1 also suggest that there is some negative skewness in returns (propensity for negative returns to occur greater than positive returns), which is in line with that reported by Whaley. This is expected for the XBW in particular since a buy-write strategy truncates the upper end of the index distribution. Merton, Scholes and Gladstein (1978) found that, for a covered call strategy, skewness was initially negative but became slowly positive when deeper out-of-the-money call options were.

The results reported in Table 1 are stronger than those reported in the US market by Whaley. He finds that while the index-only and the buy-write portfolios generate similar returns, 1.187 per cent versus 1.106 per cent, over the period June 1988 to December 2001 (approximately 14 per cent per annum); the standard deviation of returns on the buy-write portfolio is smaller than the standard deviation of returns on the index portfolio. On an

equivalent annual basis, the standard deviation of return on the index portfolio in the US was 14.21 per cent as compared to that of the buy-write portfolio that stood at 9.22 per cent (similar to the annual risk reported here for the Australian equivalent) evidently highlighting the buy-write strategy's risk reducing properties.

Chart 1 depicts the rolling 3-year annualised returns and risk since 31 December 1991. The XBW has essentially outperformed the CAI until the bull market of 2003 began upon which the underlying index has been the better performer. This of course underlines the buy-write strategy's main defect in that it is unsuited, generally, to strong bull markets. 
What is interesting here is that the lead up to the technology bubble during 2000 saw underlying rolling average returns on the benchmark index actually decline despite the euphoric optimism that continued to drive markets higher. This observation clearly shows the market in a distribution phase: "smart money" exiting the market replaced by uninformed investors who perpetuated the bubble.

In contrast, the XBW provided the better return potential over this period and its aftermath. Unlike the US market at this time, returns on the Australian equities remained positive during the resulting bear market and were actually just above the prevailing risk-free rate of return. In terms of risk, the rolling 3-year annualised standard deviations; the XBW has exhibited consistently lower volatility compared to the underlying index.

\subsection{Portfolio Performance}

Table 2 evaluates the performance of the two index strategies using the measures outlined in Section 3.3 in both the standard deviation and semi-standard deviation framework. As with the Whaley study, the results here support two conclusions. The first is the confirmation that the risk-adjusted performance of the buy-write strategy is positive and significant. A comparison of Sharpe and $\mathrm{M}^{2}$ ratios for the Accumulation Index and buy-write portfolio confirms that the risk-adjusted performance of the latter outperforms the risk-adjusted performance of the former on a mean/standard deviation basis and mean/semi-standard deviation basis. Using the former measure, the annualised outperformance ranges between 5.63 per cent and 6.81 per cent. With the latter measure, the annualised outperformance averages almost 3.30 per cent per annum.

The second conclusion concerns measures based on semi-standard deviation that give weaker results than those measures using standard deviation to the extent 
that index returns are slightly negatively skewed. Due to the greater occurrences of negative returns, the two measures of risk should differ simply reflecting any skewness present. For example, from Jensen's Alpha, the calculation of beta (through regression analysis) gives a value of 0.552 using mean-standard deviation and 0.595 when using mean/semi-standard deviation, however the difference between the alpha coefficients suggests a skewness penalty exists of about 4 basis points per day.

This penalty can be interpreted as the cost of decreasing risk; whilst overall risk has decreased, the propensity for negative returns has increased. Given that investors are generally risk averse, they should be compensated for this by higher returns, which, in the mean/variance framework, can be shown as a decrease in the cost of returns. Calculating the daily variance $\left(\sigma^{2}\right)$ to return ratio for both the XBW and the CAI, shows that the average cost of returns for the former is almost $50 \%$ less than the latter $(6.4130 \% \mathrm{v} 12.3354 \%)$, which confirms the findings of Morad and Naciri (1990).

\subsection{Portfolio Diversification with an Index Buy-write Strategy}

Callan and Associates (2006) showed that the buy-write characteristic of the $\mathrm{BXM}$ reduces correlation with both domestic and international equity markets, which therefore offers the potential for diversification. The correlation between the XBW and CAI is approximately 0.73 indicating that the addition of the XBW to a portfolio of blue chip equities would deliver further diversification benefits. This less than perfect correlation is due to the premium received from writing call options and the truncated upside return potential leading to an overall modified total return distribution.

Chart 2 shows how the MV efficient frontier expands when the XBW is added to an investment portfolio consisting of a mix of cash and the top 200 Australian 
stocks. The addition of the XBW to such a portfolio would have generated significant improvement in the risk-adjusted performance over the past 15- years. It is interesting to note that since the $\mathrm{XBW}$ offers higher returns for a reduction in risk compared to the underlying index any positively weighted combination of these two assets will not create an efficient portfolio. In fact, the only way to create an efficient frontier is to short sell the S\&P/ASX 200 Index and invest the proceeds into the XBW.

\section{The Buy-write Strategy and the Efficient Market Hypothesis}

This study effectively asserts that the buy-write index strategy produces abnormal returns compared to the index only portfolio. If the underlying index were in fact a close proxy to the market model then this result would be seen to violate the EMH. This hypothesis asserts that since markets are efficient, investors are rational, and prices reflect all available information. Attempts by investors to obtain abnormal returns through either trading strategies or fundamental analysis will prove to be futile after including trading costs and adjusting for risks. Practitioners often find that empirical phenomena are difficult to reconcile within the framework of traditional finance theory. This study suggests that there is indeed "free money left on the table" during the time period from writing options over an investible index. This disconnect can be explained by evaluating the assumptions of traditional finance theory such as, the demand curves for stocks are kept flat by riskless arbitrage between perfect substitutes. In reality, individual stocks do not have perfect substitutes. As a result, arbitrageurs and computerised trading programs that instantaneously capture risk-free arbitrage opportunities face market frictions that inhibit the ability to exploit many inefficiencies, such as fund managers' inelastic demand for index options for example.

The results in this paper support the case that traditional finance theory, i.e. $\mathrm{EMH}$, does not adequately explain the idiosyncrasies of the real world. However, the 
identification of behaviour that violates efficient market assumptions may indeed indicate opportunities to exploit market inefficiencies and generate consistent abnormal returns with lower risk. The following framework identifies exactly how the assumptions of EMH are violated by fund managers' inelastic demand for index options that frequently occurs when there is a clear need to boost returns on large, well-diversified stock portfolios, during periods of trendless market activity.

There are three main assumptions underpinning the EMH that are regularly violated in the real world: homogeneous expectations, investment markets are frictionless, i.e. there are no transaction costs, or restrictions on short-sales and that perfect competition exists, whereby market participants, regardless of their size, can transact without affecting prices. Dealing with each assumption in turn, it is a difficult proposition to expect all investors to share the same belief about the expected return and risk involved in a particular investment. For example, arbitrageurs and index managers rationale for trading is inconsistent and biased with Brock and Hommes (1998) illustrating diversity in agents' beliefs, and Guilaume et al (1995) arguing that participants' objectives and time horizons exhibit heterogeneity. Trading costs, short sale restrictions, and imperfect hedges are institutional frictions that all exist in the Australian financial market, which inhibit market participants (arbitrageurs) from exploiting inefficiencies since they wish to avoid unhedged risks. Similarly, in markets with excellent liquidity, large investors impact asset prices in a far more material fashion than other investors.

This study suggests that abnormal returns can be achieved by implementing a buy-write options trading strategy that boosts the returns available on a large, welldiversified stock portfolio. As mentioned earlier, the average monthly return from the buy-write portfolio was 1.11 per cent, which translated into a total annual return from the trading strategy of 14.20 per cent with the largest daily loss of ( 7.25 per cent). The 
average annual abnormal return was 1.31 per cent, which was accompanied by a visible reduction in the standard deviation of returns. The buy-write portfolio was profitable and exceeded the return on the index portfolio over 47 per cent of the time. As demonstrated by this example, in which violations of efficient market assumptions are identified and exploited (namely call option overpricing), the ability to recognize and understand violations of traditional finance theory and EMH can reveal unidentified market inefficiencies that can be captured with profit.

It should be pointed out that proponents of EMH believe that excess returns are caused by incorrect or inadequate "risk-adjusted" performance measurements. Lhabitant (1998) believes that MV performance measures give equal weight to either positive or negative returns through truncation of one side of the distribution. An important consequence, Lhabitant (1998) and others believe is that when the underlying asset for the options is the market portfolio (i.e. an index), the buy-write strategy will appear to beat the non-optioned portfolio, i.e. the market itself. Using options in a MV context (e.g. Sharpe ratio), "beating the market is easy", which is in contradiction to EMH.

\section{Summary and Conclusions}

This study examines the performance of a buy-write strategy involving the purchase of the index portfolio and writing one just-out-of-the-money index call option. Specifically, the paper attempted to determine whether the buy-write strategy can be used to compose a more efficient risk/return portfolio than would be the case with an index-only portfolio. The methodology used was that of Whaley (2002) in which three portfolios were constructed consisting of the buy-write index, the market index and a bank bill. 
Our results exceed those of Whaley, on both a total risk and systematic riskadjusted basis the buy-write strategy outperforms the index portfolio. Consistent with the US market, we conclude that a buy-write strategy appears to be a profitable wealth creation tool in the Australian market.

The Australian index buy-write/covered call strategy is limited by the relatively small and segmented local options market. Liquidity is scarce and market makers dominate, which leads to frequent mispricing that tends to deter large-scale participation by the wider investment community. Whether this frequent mispricing is due to the thinness of trading in Australia and the lack of say semi-strong form market efficiency, arbitrage opportunities exist using the buy-write strategy and one would expect that as the Australian investor gains greater knowledge and sophistication, such opportunities will disappear or be arbitraged away over time. In addition, whilst this study ignores transaction costs for simplicity, they are subject to a minimum floor before rising proportionately with the value traded. In general, Australian option premiums tend to be small so the investor needs to be trading a substantial number of contracts before the strategy becomes worthwhile after considering trading costs. Buy-write strategies in this instance will probably be used entirely for risk management in the need to avoid naked calls and the need to have an assurance that the underlying asset can be delivered when and if required.

Further work is required in the Australian options market specifically to determine the extent of index call and put mispricing and its effect upon the abnormal returns generated from a simple index strategies. Whether the evident mispricing is due to competition among portfolio managers for insurance or the lack of liquidity remains unclear. To the authors' knowledge there is no extant study to date that clearly addresses these issues and this might be a fruitful area of future research. 


\section{References}

Bollen, N, P, B and Whaley, R, E 2004, 'Does Net Buying Pressure Affect the Shape of Implied Volatility Functions?' Journal of Finance, Vol. LIX, No. 2, April, pp. $711-753$.

Bookstaber, R and Clarke, R, G 1984, 'Option portfolio strategies: Measurement and evaluation', Journal of Business, Vol. 57, pp. 469 - 92.

Bookstaber, R and Clarke, R, G 1985, 'Problems in evaluating the performance of portfolios with options', Financial Analysis Journal, Jan - Feb, pp. 435 - 450.

Brock, W, A and Hommes, C, H 1998, 'Heterogeneous Beliefs and Routes to Chaos in a Simple Asset Pricing Model', Journal of Economic Dynamics and Control, 22, pp. $1235-1274$.

Callan and Associates 2006, An Historical Evaluation of the CBOE S\&P 500 Buy Write Index Strategy, [Brochure], Callan.

Chicago Board Options Exchange 2002, The CBOE BuyWrite Monthly Index (BXM), [Brochure], CBOE.

Guillaume, D. M, Dacorogna, M, M, Dave, R, D, Muller, U, A, Olsen, R, B and Pictet, O, V 1995, 'From the Bird's Eye to the Microscope: A Survey of New Stylized facts of the Intra-Daily Foreign Exchange Markets', mimeo, Fordham $\begin{array}{llll}\text { University. } & \text { Retrieved } & \text { October } & \text { 21, 2006, }\end{array}$ http://www.bnet.fordham.edu/Academics/Colleges_Graduate_S/Graduate_Professi $\underline{\text { on/GBA/index.html }}$

Jarnecic, E, 2004, 'Return and Risk of Buy-Write Strategies using Index Options: Australian Evidence' Research Project, SIRCA. Retrieved September 21, 2006, from http://www.sirca.org.au/research/index.html 
Lhabitant, F. S 2000, 'Derivatives in Portfolio Management: Why Beating the Market is Easy', Derivatives Quarterly, Winter, pp. 39 - 45.

Merton, R C 1973, 'Theory of Rational Option Pricing'. Bell Journal of Economics and Management Science, 4 (1), pp. 141 - 183.

Merton, R, C, Scholes, M, S and Gladstein, M, L 1978, 'The return and risks of alternative call option strategies', Journal of Business, Vol. 51, no. 2, pp. 183 - 242.

Merton, R, C, Scholes, M, S and Gladstein, M, L 1982, 'The return and risks of alternative put option strategies', Journal of Business, Vol. 55, no. 1, pp. 1-43.

Morard, B and Naciri, A 1990, 'Options and investment strategies', Journal of Futures Markets, Vol. 10, pp. 505 - 517.

Standard and Poor's 2006, S\&P/ASX200: The Institutional Benchmark for the Australian Market, [Brochure], S\&P.

Whaley, R, E 2002, 'Return and Risk of CBOE Buy Write Monthly Index', Journal of Derivatives, Winter, pp. 35-42. 
Table 1: Summary Statistics for XBW and alternative portfolios since December 31, 1991

\begin{tabular}{|c|c|c|c|}
\hline & $\begin{array}{c}\text { S\&PIASX } \\
\text { XBW }\end{array}$ & $\begin{array}{l}\text { Comp. Acc. } \\
\text { Index }\end{array}$ & $\begin{array}{c}\text { 90-day Bank } \\
\text { Bills }\end{array}$ \\
\hline \multicolumn{4}{|l|}{ Monthly Statistics } \\
\hline Average Compound Return & $1.62 \%$ & $1.48 \%$ & $0.00 \%$ \\
\hline Median Compound Return & $1.84 \%$ & $1.75 \%$ & $0.00 \%$ \\
\hline Standard Deviation & $2.67 \%$ & $3.53 \%$ & $0.34 \%$ \\
\hline Downside Risk (Relative to zero) & $2.17 \%$ & $2.52 \%$ & $0.05 \%$ \\
\hline Excess Return (over CAI) & $0.14 \%$ & & \\
\hline \multicolumn{4}{|l|}{ Annual Statistics } \\
\hline Average Compound Return & $21.24 \%$ & $19.23 \%$ & $0.01 \%$ \\
\hline Median Compound Return & $24.48 \%$ & $23.08 \%$ & $0.00 \%$ \\
\hline Standard Deviation & $9.24 \%$ & $12.24 \%$ & $1.16 \%$ \\
\hline Downside Risk (Relative to zero) & $7.51 \%$ & $8.73 \%$ & $0.17 \%$ \\
\hline Excess Return (over CAI) & $2.01 \%$ & & \\
\hline \multicolumn{4}{|l|}{ Other Statistics (Daily Data) } \\
\hline Minimum Return & $-7.25 \%$ & $-7.43 \%$ & $-2.09 \%$ \\
\hline Maximum Return & $5.68 \%$ & $6.22 \%$ & $0.70 \%$ \\
\hline$\%$ Returns $>0$ & $57.29 \%$ & $54.27 \%$ & $42.26 \%$ \\
\hline$\%$ Excess Returns (over CAI) $>0$ & $47.19 \%$ & & \\
\hline Correlation (to CAI) & 0.7282 & 1.000 & 0.0528 \\
\hline Skewness & -0.62 & -0.42 & -7.62 \\
\hline Excess Kurtosis & 18.64 & 5.17 & 212.58 \\
\hline Jarque-Bera Test Statistic & 54,617 & 4,300 & $7,112,640$ \\
\hline
\end{tabular}

Table 2: Daily Risk Adjusted Performance Measures

\begin{tabular}{|c|c|c|c|c|c|}
\hline \multirow[b]{2}{*}{ Risk Measure } & \multirow[b]{2}{*}{ Index } & \multicolumn{2}{|c|}{ Total Risk Based } & \multicolumn{2}{|c|}{ Systematic Risk Based } \\
\hline & & $\begin{array}{c}\text { Sharpe } \\
\text { Ratio }\end{array}$ & M2 & $\begin{array}{c}\text { Treynor } \\
\text { Ratio }\end{array}$ & $\begin{array}{c}\text { Jensen's } \\
\text { Alpha }\end{array}$ \\
\hline \multirow{3}{*}{ Standard Deviation } & XBW & 0.090638 & $0.021740 \%$ & 0.000955 & $0.026141 \%$ \\
\hline & CAI & 0.062440 & & 0.000872 & $\beta: 0.55234$ \\
\hline & Excess & 0.028198 & & 8.3E-05 & \\
\hline \multirow{3}{*}{$\begin{array}{l}\text { Semi-standard } \\
\text { Deviation }\end{array}$} & XBW & 0.111529 & $0.013179 \%$ & 0.000886 & $0.012437 \%$ \\
\hline & CAI & 0.087559 & & 0.000809 & $\beta: 0.595228$ \\
\hline & Excess & 0.023970 & & 7.7E-05 & \\
\hline
\end{tabular}




\section{Chart 1: Rolling 3-year Annualised Returns \& Risk}
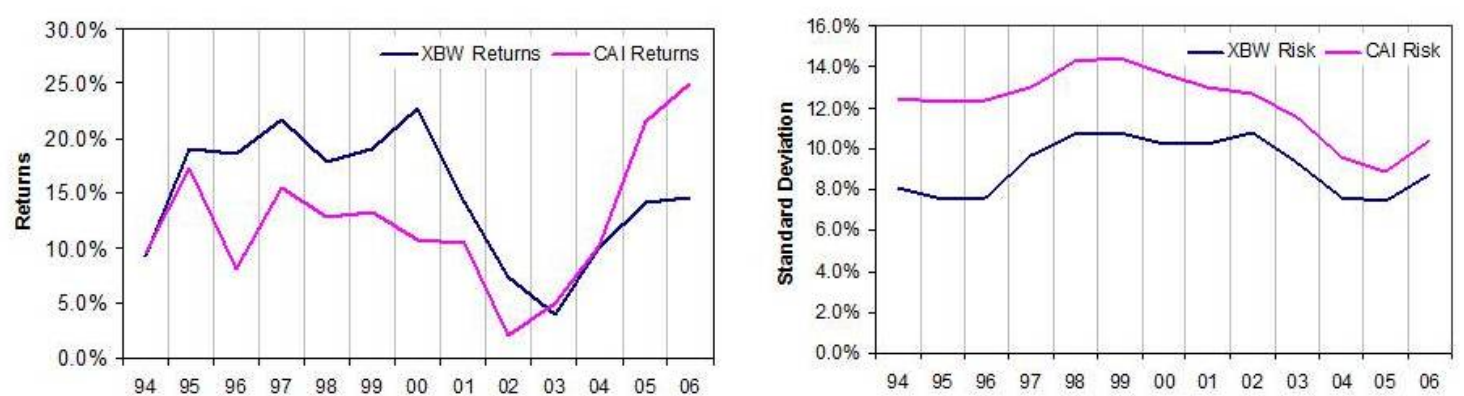

\section{Chart 2: The Mean-Variance Efficient Frontier}

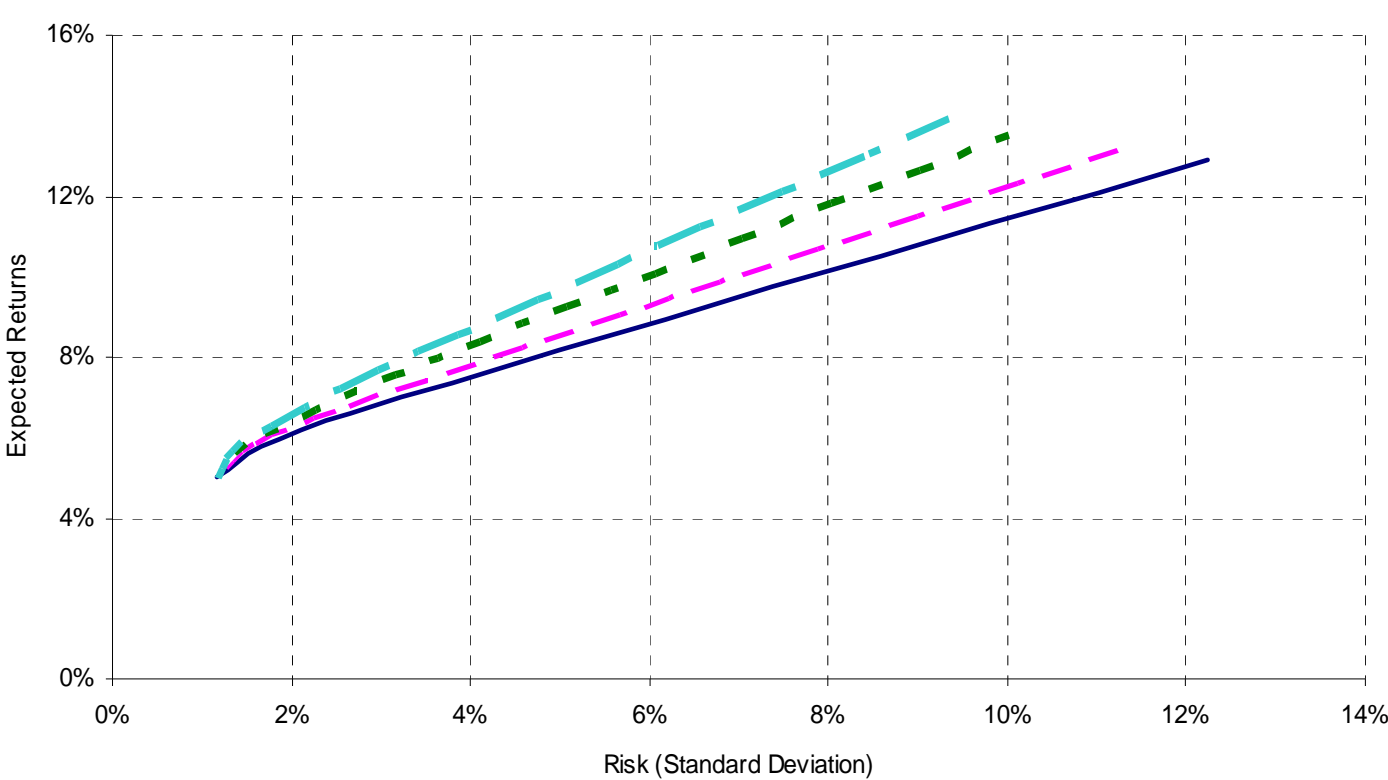

$100 \% \mathrm{CAl}+0 \% \mathrm{XBW}--80 \% \mathrm{CAI}+20 \% \mathrm{XBW}=-50 \% \mathrm{CAl}+50 \% \mathrm{XBW}=20 \% \mathrm{CAl}+80 \% \mathrm{XBW}$ 